\title{
AVALIAÇÃO FÍSICO-QUÍMICA E SENSORIAL DE BISCOITOS TIPO COOKIES ELABORADOS COM FOLHA DE Moringa oleifera
}

\author{
ALINE TAKAOKA ALVES BAPTISTA* \\ MARIANA OLIVEIRA SILVA** \\ ROSÂNGELA BERGAMASCO*** \\ ANGÉLICA MARQUETTOTI SALCEDO VIEIRA***
}

\begin{abstract}
Este trabalho teve como objetivo a produção de biscoitos tipo cookie com substituição parcial de farinha de trigo pelo pó da folha de Moringa oleifera. Foram preparadas três formulações de biscoito tipo cookie com substituição de 3,64, 7,27 e 9,09\% de farinha de trigo por pó da folha de Moringa oleifera, correspondentes às formulações F1, F2 e F3, respectivamente. Na avaliação sensorial não houve diferença de aceitação ao nível de $5 \%$ entre as 3 formulações. Com base nesse resultado optou-se por utilizar a F3 (com maior nível de substituição) para ser comparada à formulação padrão (FP), mediante análises físico-químicas. Análises de cinzas, umidade, atividade de água, pH e acidez titulável total das formulações FP e F3 foram realizadas, obtendo-se valores próximos nas duas formulações. Valores estimados de carboidratos, proteínas, fibras e gorduras foram calculados, tendo a F3 apresentado maiores quantidades de fibras e proteínas em relação à FP. Os teores de gordura mantiveramse semelhantes e em relação aos carboidratos verificou-se maior quantidade na FP em comparação com a F3. Assim, apesar da folha de Moringa apresentar nutrientes importantes à alimentação, há a necessidade de análises físico-químicas a fim de se comprovar o enriquecimento dos alimentos elaborados com essa planta.
\end{abstract}

PALAVRAS-CHAVE: Moringa oleifera; COOKIE; ANÁLISE SENSORIAL.

* Engenheira deAlimentos, Universidade Estadual de Maringá(UEM), Maringá,PR (e-mail:alinetakaoka_17@ hotmail.com).

** Mestranda em Ciência de Alimentos, UEM, Maringá, PR (e-mail: mariana_osilva@hotmail.com).

*** Professor Adjunto, Departamento de Engenharia Química, UEM, Maringá, PR (e-mail: rosangela@deq. uem.br).

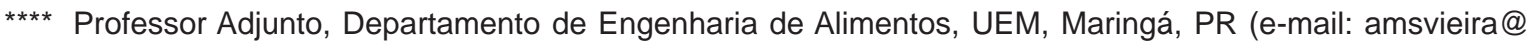
uem.br). 


\section{INTRODUÇÃo}

Moringa oleifera Lamarck (MO), planta pertencente à família das Moringaceae, é nativa da Índia e amplamente cultivada nos trópicos de todo o mundo (KARADI et al., 2006 apud MADRONA, 2009). No Brasil, foi introduzida como planta ornamental por volta de 1950 e desde então tem sido amplamente cultivada devido ao seu alto valor alimentício, principalmente das folhas, ricas em caroteno, ácido ascórbico e ferro (MAKKAR e BECKER, 1996; BEZERRA et al., 2004 apud BARRETO et al., 2009). Essa planta cresce facilmente, mesmo em solos pobres, atingindo cerca de 10 metros de altura (DELDUQUE, 2000 apud PINTO e HERMES, 2006). Apresenta longas vagens verdes, sementes aladas, folhas grandes e flores brancas perfumadas (JOLY, 1979 apud MADRONA, 2009).

Ao contrário das plantas nativas do semi-árido, a moringa não perde as suas folhas no período seco e dessa forma pode representar alternativa nutritiva para grande parte do território brasileiro. Trata-se de planta perene resistente à seca, pouco exigente quanto ao solo e adubação, tolerante às pragas e doenças, além de ser utilizada como cerca viva e quebra-vento em algumas regiões (SILVA e KERR, 1999 apud ALVES et al., 2005). Com base nos motivos apresentados anteriormente, a MO pode ser considerada alternativa alimentar estratégica em países em desenvolvimento (FUNDAÇÃO DEUS MAR QUEIRÓS, 2010). Suas sementes são usadas no tratamento de água por floculação e sedimentação, visto que é capaz de eliminar a turvação, micro partículas, fungos e bactérias em substituição ao sulfato de alumínio. O óleo contido nessa semente é de excelente qualidade, podendo ser usado para cozinhar e confeccionar sabão, encontrando aplicação na indústria de cosméticos e também na indústria farmacêutica. As frutas, sementes, folhas e flores são consumidas como legumes nutritivos em alguns países, já as vagens verdes cozidas e sementes maduras (torradas) são ingeridas como verduras (CHAWLA et al., 1988; HERDES, 1994, apud ALVES et al., 2005). Por todas essas funcionalidades, essa árvore apresenta importância econômica significante com diversas utilidades na indústria e na medicina (MAKKAR e BECKER, 1997). De todas as partes da MO com grande valor nutricional, atenção especial é dada às suas folhas devido ao seu elevado teor de vitaminas, minerais, proteínas e aminoácidos (SILVA e VIANA 2009).

No Brasil, há um esforço no sentido de difundir a moringa como hortaliça rica em vitamina A (KERR et al., 1998; SILVA e KERR, 1999). Suas folhas, com cerca de 23.000 Ul de vitamina A, sobressaem-se entre olerícolas consagradas como brócolis, cenoura, couve, espinafre e alface, que apresentam, respectivamente, 5.000; 3.700; 2.200; 1.900; 1.000 UI de vitamina A (SILVA e KERR, 1999 apud ROCHA e PEREIRA, 2009). Análises nutricionais indicam a riqueza de suas folhas, contendo igualmente todos os aminoácidos essenciais, o que não é comum em fontes vegetais (SILVA e VIANA 2009). Existem diferentes formas de uso de suas folhas como alimento, podendo ser preparadas como espinafre ou até mesmo em pó, depois de secas, piladas e adicionadas em sopas e molhos (FUNDAÇÃO DEUS MAR QUEIRÓS, 2010). Uma só colher de chá das folhas contém todas as vitaminas e minerais necessários por dia aos indivíduos, assim como grande parte das proteínas, do ferro e do cálcio necessários diariamente (FUGLIE, 2005). O pó das folhas secas é concentrado e dessa forma apresenta maiores quantidades de muitos nutrientes citados acima, exceto de vitamina C (MATHUR, 2005). As informações sobre as folhas de MO frescas foram retiradas de Gopalan, Sastri e Balasubramanian (1989), baseadas principalmente em análises efetuadas no Instituto Nacional de Nutrição em Hyderabad, Índia. Já as informações sobre as folhas de MO secas são de Fuglie (2002), com base principalmente em análises patrocinadas pelo Serviço Mundial das Igrejas e o Departamento de Engenharia da Universidade de Leicester.

A Tabela 1 apresenta a quantidade de nutrientes em folhas frescas e secas de Moringa oleifera. 


\section{TABELA 1 - QUANTIDADES DE NUTRIENTES EM FOLHAS FRESCAS E SECAS DE moringa oleifera}

\section{Folhas frescas ${ }^{1}$ \\ (Gramas por grama, as folhas frescas contêm aproximadamente)}

4 vezes a vitamina $A$ de cenouras

7 vezes a vitamina $C$ de laranjas

4 vezes o cálcio do leite

3 vezes o potássio de bananas

$3 / 4$ do ferro de espinafre

2 vezes a proteína de iogurte

\section{Folhas secas ${ }^{2}$ \\ (Gramas por grama, as folhas secas contêm aproximadamente)}

\author{
10 vezes a vitamina $A$ de cenouras \\ $1 / 2$ de vitamina $C$ de laranjas \\ 17 vezes o cálcio do leite \\ 18 vezes o potássio de bananas \\ 25 vezes o ferro de espinafre \\ 9 vezes a proteína de iogurte
}

Fonte: GOPALAN, SASTRI e BALASUBRAMANIAN, 1989¹; FUGLIE, $2002^{2}$.

Dentre os minerais e vitaminas, presentes nas folhas de $\mathrm{MO}$, podem ser citados: vitamina $\mathrm{A}$, vitamina B1, vitamina B2, vitamina B3, vitamina $C$, cálcio, cromo, cobre, ferro, magnésio, manganês, fósforo, potássio, proteína e zinco (MATHUR, 2005).

Devido à riqueza de nutrientes que a folha apresenta, grande é o interesse em utilizá-la em diferentes alimentos. $\mathrm{O}$ uso da folha de $\mathrm{MO}$ tem sido muito estimulado como forma de aperfeiçoar o aproveitamento da planta, já que as sementes, flores e vagem são utilizadas na alimentação. Por não exigir cuidados rigorosos (muito resistente a seca e doenças) e ser totalmente aproveitável, torna-se alternativa interessante para a alimentação humana. Estudos vêm relatando o uso do pó da folha de MO em alimentos como pães (BRITO e TEIXEIRA, 2009) e sorvetes (OLIVEIRA, TEIXEIRA e PEREIRA, 2009).

Dentre os inúmeros tipos de alimentos, os biscoitos tipo cookies chamam a atenção por conta de suas peculiaridades. Biscoitos do tipo cookie satisfazem os requisitos expostos anteriormente, apresentando-se como produto de grande consumo e ampla aceitação por pessoas de todas as idades, particularmente por crianças (COSTA, 2008).

Crescentes são as pesquisas e trabalhos visando melhor conhecimento de todos os recursos que a Moringa oleifera Lam. pode oferecer, juntamente com o estudo de melhores formas de aplicação desses recursos em alimentos de maneira que sejam aceitáveis pelos consumidores. Assim, o uso do pó da folha de Moringa oleifera Lam. em biscoitos do tipo cookie surge como forma de ampliar seu aproveitamento na alimentação humana.

Este trabalho teve como objetivo a produção de biscoitos tipo cookie com a substituição parcial da farinha de trigo por pó da folha de Moringa oleifera, bem como a avaliação sensorial do produto obtido.

\section{MATERIAL E MÉTODOS}

\subsection{MATERIAL}

As folhas de Moringa oleifera foram adquiridas na fazenda de ensino pertencente à Universidade Estadual de Maringá. A farinha de trigo, o açúcar cristal, o açúcar mascavo, o chocolate em pó, a margarina, os ovos, o fermento, a canela, a baunilha e o sal utilizados na elaboração dos cookies foram adquiridos no comércio da cidade de Maringá.

Para a realização das análises de $\mathrm{pH}$, atividade de água, umidade e cinzas foram utilizados os equipamentos: pHmetro HANNA, AW Sprint TH-500/NOVASINA, estufa para esterilização e secagem, LS LOGEN SCIENTIFIC, e mufla HW 1000. Para o preparo do pó da folha de MO e 
do cookie utilizou-se desidratadora da marca Pardal, modelo PE 100, e forno elétrico Philco 42 L, respectivamente.

\subsection{PREPARO DO PÓ DA FOLHA DE Moringa oleifera}

Após a colheita das folhas efetuou-se a separação dos galhos para que não houvesse interferência no momento da fabricação do pó da folha MO. Em seguida, realizou-se a higienização das folhas de $\mathrm{MO}$ em solução sanitizante de cloro ativo a 200 ppm por 15 minutos.

O material higienizado passou pela desidratadora com circulação de ar na temperatura de $35^{\circ} \mathrm{C}$ durante 6 horas. As folhas desidratadas foram trituradas em liquidificador até que se reduzissem a pó, sendo peneiradas visando homogeneização.

Acondicionou-se o pó da folha de $\mathrm{MO}$ em recipiente livre de contaminações, umidade ou qualquer outro fator que acarretasse perda de qualidade.

\subsection{PREPARO DOS BISCOITOS TIPO COOKIE}

A fabricação dos biscoitos tipo cookie ocorreu de maneira artesanal com ingredientes comuns. Todos os ingredientes foram pesados de maneira a se obter maior padronização entre as receitas e misturados até que se obtivesse massa homogênea. Efetuou-se a modelagem manual dos cookies com cuidado para que todos se apresentassem de maneira mais homogênea possível, com quantidade aproximada de 15 gramas.

O assamento ocorreu em forno elétrico pré-aquecido, sendo os cookies colocados em assadeiras untadas com manteiga e farinha. As temperaturas foram rigorosamente controladas e os cookies assados por 25 minutos, sendo os 10 primeiros minutos de assamento a $150^{\circ} \mathrm{C}$ e os 15 minutos restantes a $180^{\circ} \mathrm{C}$.

Produziu-se o cookie padrão, designado como FP, sem a substituição parcial da farinha de trigo pelo pó da folha de Moringa oleifera e três formulações com a farinha de trigo substituída em 3,64, 7,27 e 9,09\% pelo pó da folha de Moringa oleifera (F1, F2 e F3, respectivamente). As quantidades em g/100 g das formulações citadas anteriormente encontram-se na Tabela 2.

\section{TABELA 2 - QUANTIDADE EM g/100 g DE MATÉRIA-PRIMA USADA NA ELABORAÇÃO DOS COOKIES}

\begin{tabular}{|c|c|c|c|c|}
\hline Ingredientes & $\begin{array}{l}F P \\
(g / 100 \mathrm{~g})\end{array}$ & $\begin{array}{l}F 1 \\
(g / 100 \mathrm{~g})\end{array}$ & $\begin{array}{l}F 2 \\
(g / 100 \mathrm{~g})\end{array}$ & $\begin{array}{l}F 3 \\
(g / 100 \mathrm{~g})\end{array}$ \\
\hline Açúcar cristal & 17,67 & 17,67 & 17,67 & 17,67 \\
\hline Açúcar mascavo & 11,78 & 11,78 & 11,78 & 11,78 \\
\hline Baunilha & 0,01 & 0,01 & 0,01 & 0,01 \\
\hline Canela & 0,44 & 0,44 & 0,44 & 0,44 \\
\hline Chocolate & 11,78 & 11,78 & 11,78 & 11,78 \\
\hline Farinha & 32,40 & 31,22 & 30,05 & 29,46 \\
\hline Fermento & 0,69 & 0,69 & 0,69 & 0,69 \\
\hline Margarina & 8,98 & 8,98 & 8,98 & 8,98 \\
\hline Moringa & 0 & 1,18 & 2,36 & 2,95 \\
\hline Ovos & 16,20 & 16,20 & 16,20 & 16,20 \\
\hline Sal & 0,03 & 0,03 & 0,03 & 0,03 \\
\hline
\end{tabular}




\subsection{ANÁLISE SENSORIAL}

Efetuou-se a análise sensorial com 50 julgadores, não treinados, universitários voluntários da Universidade Estadual de Maringá, utilizando o teste de escala hedônica para verificar o nível de aceitação dos cookies. Foram servidas três amostras de cookies com, aproximadamente, 15 gramas cada, correspondentes as formulações F1, F2 e F3. Essas amostras foram apresentadas aos julgadores em copos descartáveis, codificados com número de três dígitos, e devidamente aleatorizadas a fim de se minimizar possíveis erros na análise.

Os julgadores expressaram o grau de aceitação do produto em relação aos atributos sabor e textura, mediante escala mista de nove pontos, sendo 1 para "desgostei muitíssimo" e 9 para "gostei muitíssimo" ( MONTEIRO, 2005).

\subsection{ANÁLISES FÍSICO-QUÍMICAS}

Todas as análises físico-químicas das amostras foram realizadas em triplicata e os resultados expressos como média \pm desvio padrão.

As análises de cinzas, umidade, $\mathrm{pH}$ e acidez titulável total foram efetuadas conforme metodologias do Instituto Adolfo Lutz (2005).

A análise da atividade de água ocorreu em equipamento AW Sprint TH-500/NOVASINA, utilizando-se as amostras de cookie na temperatura de $25^{\circ} \mathrm{C}$ de acordo com o procedimento descrito em seu manual (NOVASINA, 2004).

O cálculo estimado da quantidade de proteína, carboidrato, gordura e fibra foi realizado com base nas informações oferecidas pelos fabricantes dos ingredientes utilizados na elaboração dos cookies, juntamente com as informações sobre as folhas de MO secas (FUGLIE, 2002).

\subsection{ANÁLISE ESTATÍSTICA}

Os dados obtidos foram avaliados por meio da análise de variância (ANOVA) com nível de 5\% de significância, fazendo-se uso do programa Microsoft Office Excel 2007 (MONTEIRO, 2005).

\section{RESULTADOS E DISCUSSÃO}

\subsection{ANÁLISE SENSORIAL}

As médias das notas dadas pelos julgadores para os atributos sabor e textura das diferentes formulações são apresentadas na Tabela 3.

TABELA 3 - MÉDIAS DAS NOTAS DAS DIFERENTES FORMULAÇÕES

\begin{tabular}{llll}
\hline Parâmetro & F1 & F2 & F3 \\
\hline Sabor & $8,10^{\mathrm{a}}$ & $7,82^{\mathrm{a}}$ & $7,94^{\mathrm{a}}$ \\
Textura & $7,88^{\mathrm{a}}$ & $7,70^{\mathrm{a}}$ & $7,82^{\mathrm{a}}$ \\
& & & \\
\hline
\end{tabular}

Letras iguais na mesma linha não apresentam diferença significativa ao nível de 5\%. 
Para o atributo sabor, a formulação F1 com substituição parcial de $3,64 \%$ de farinha de trigo pelo pó da folha de Moringa oleifera (Tabela 3) alcançou maior média de nota seguida pelas formulações F3 e F2 (com substituição de 9,09\% e 7,27\% de farinha de trigo por pó da folha de $\mathrm{MO}$, respectivamente). Mesmo apresentando característica peculiar devido à substituição parcial de farinha de trigo por pó da folha de $\mathrm{MO}$, os cookies obtiveram boas notas para os atributos sabor e textura.

O teste de ANOVA não detectou diferença significativa para os atributos sabor e textura ao nível de 5\% de significância entre as três formulações com substituição parcial de 3,64\%, 7,27\% e $9,09 \%$ de farinha de trigo por pó da folha de Moringa oleifera. Verificou-se a possibilidade de substituição da farinha de trigo pelo pó da folha de MO nos percentuais usados sem qualquer alteração desagradável no sabor e na textura dos cookies.

\subsection{ANÁLISES FÍSICO-QUÍMICAS}

Como não houve diferença significativa de aceitação entre as formulações na análise sensorial escolheu-se a F3, com maior substituição de farinha de trigo por pó da folha de Moringa oleifera para ser comparada com a formulação padrão nas análises físico-químicas.

Os valores relativos de cinzas, umidade, atividade de água, pH e acidez titulável total das formulações FP e F3 são apresentados na Tabela 4.

\section{TABELA 4 - PARÂMETROS FÍSICO-QUÍMICOS DOS COOKIES FP E F3}

\begin{tabular}{lll}
\hline Parâmetro & FP & F3 \\
\hline Cinzas (\%) & $1,35 \pm 0,05^{\mathrm{a}}$ & $1,62 \pm 0,03^{\mathrm{a}}$ \\
Umidade (\%) & $10,85 \pm 0,02^{\mathrm{a}}$ & $11,27 \pm 0,02^{\mathrm{a}}$ \\
Atividade de água & $0,522 \pm 0,00^{\mathrm{a}}$ & $0,570 \pm 0,00^{\mathrm{a}}$ \\
pH & $6,75 \pm 0,21^{\mathrm{a}}$ & $6,67 \pm 0,09^{\mathrm{a}}$ \\
Acidez titulável total $(\mathrm{mL} / 100 \mathrm{~g})$ & $1,56 \pm 0,04^{\mathrm{a}}$ & $1,65 \pm 0,04^{\mathrm{a}}$ \\
\hline
\end{tabular}

Letras iguais na mesma linha não apresentam diferença significativa ao nível de 5\%.

Por meio da Tabela 4 pode-se perceber aumento no teor de cinzas da F3 com substituição parcial de farinha de trigo por pó da folha MO $(1,62 \%)$ em relação à FP $(1,35 \%)$. Tal fato se deve à composição mineral do pó da folha de MO que auxilia o aumento do teor de cinzas observado.

Em termos de umidade, a F3 mostrou pequenas diferenças em relação à FP com valor um pouco superior nesse parâmetro. A folha de Moringa oleifera in natura com umidade de $77,30 \%$ (MOURA et al., 2009) pode gerar pó com umidade superior ao da farinha de trigo com 13\% (NEPAUNICAMP, 2006). Em relação aos valores de acidez apresentados na Tabela 5 notou-se pequena variação entre as amostras, sendo a acidez da formulação F3 levemente superior à da FP.

A Resolução n. 12/1978 da Agência Nacional de Vigilância Sanitária, que fixa padrões de identidade e qualidade de alimentos, estabelece para biscoitos umidade máxima de 14\% peso/peso, acidez em solução normal com máximo de $2,0 \mathrm{~mL} / 100 \mathrm{~g}$ e resíduo mineral fixo máximo de 3,0\% peso/peso (deduzido e sal). Os valores obtidos nas análises de cinzas, umidade e acidez titulável total das formulações FP e F3 estão de acordo com a referida legislação (BRASIL, 1978). 
$\mathrm{Em}$ relação ao $\mathrm{pH}$, as duas formulações obtiveram valores muito próximos (FP com $\mathrm{pH}$ 6,75 ligeiramente mais elevado que a F3 com 6,67) e enquadrados na faixa normal para biscoitos (entre 6,5 e 8,0), conforme Maciel et al. (2008).

Com base nos resultados apresentados na Tabela 4 houve pequeno aumento da atividade de água da F3 em relação à FP. Contudo, os valores encontrados para esse parâmetro não são considerados propícios à multiplicação de microorganismos. Como os mesmos podem permanecer viáveis por tempo prolongado, as Boas Práticas de Fabricação e o acondicionamento correto do produto acabado tornam-se aspectos de grande importância (UFRJ, 2010). Esse tipo de análise assume relevância, pois seus resultados estão diretamente relacionados à vida-de-prateleira do produto.

Por meio do teste ANOVA não foi detectada diferença significativa nos parâmetros físicoquímicos (ao nível de 5\%) entre as formulações FP e F3.

Os valores estimados em porcentagem de carboidratos, proteínas, gorduras e fibras dos cookies são apresentados na Tabela 5.

\section{TABELA 5 - QUANTIDADES EM PORCENTAGEM DE CARBOIDRATOS, PROTEÍNAS, GORDURAS E FIBRAS NOS COOKIES FP E F3}

\begin{tabular}{lll}
\hline Parâmetro & FP (\%) & F3 (\%) \\
\hline Carboidratos & $62,53^{\mathrm{a}}$ & $61,41^{\mathrm{a}}$ \\
Proteínas & $6,05^{\mathrm{a}}$ & $6,55^{\mathrm{a}}$ \\
Gorduras & $8,81^{\mathrm{a}}$ & $8,88^{\mathrm{a}}$ \\
Fibras & $1,41^{\mathrm{a}}$ & $1,92^{\mathrm{a}}$ \\
\hline
\end{tabular}

Letras iguais na mesma linha não apresentam diferença significativa ao nível de 5\%.

A quantidade de proteínas da formulação F3 (Tabela 5) apresentou-se ligeiramente superior em comparação à FP. Essa característica pode ser explicada com base no maior percentual de proteína $(27,1 \%)$ no pó da folha de MO (FUGLIE, 2002) em relação à farinha de trigo, conforme informação do seu fabricante (10\%). As quantidades de gordura mostraram-se extremamente próximas entre as formulações (FP e F3), não apresentando diferença entre si.

Maiores valores de fibras verificados para a F3 do que para a FP são decorrentes da alta concentração de fibras $(19,2 \%)$ no pó da folha de MO (FUGLIE, 2002) em relação à farinha de trigo (2\%, conforme relatado pelo seu fabricante).

O maior valor de carboidratos obtido pela FP está relacionado ao fato do percentual de carboidratos da farinha de trigo ( $76 \%$, segundo dados do fabricante) ser superior ao do pó das folhas de MO com 38,2\% (FUGLIE, 2002). Verificou-se discreto aumento no teor de proteína e de fibra com base no uso do pó da folha de MO nos alimentos testados. Porém, aplicando-se o teste ANOVA, não houve diferença significativa ao nível de $5 \%$ nas quantidades de carboidratos, proteínas, gordura e fibras entre as formulações FP e F3.

\section{CONCLUSÃO}

Por meio dos resultados obtidos pode-se concluir que o objetivo do presente trabalho foi atingido, tendo sido elaborados biscoitos do tipo cookie com substituição parcial da farinha 
de trigo pelo pó da folha de Moringa oleifera aceitos sensorialmente. Outros estudos devem ser realizados para identificar se a porcentagem de 9,09\% seria o limite de substituição da farinha de trigo por pó de folha de MO na elaboração de cookies com sabor e textura agradáveis.

A substituição parcial de farinha de trigo por pó da folha de MO resultou em pequenas alterações nas propriedades físico-químicas dos cookies, que não acarretaram perda da característica do produto nem de sua qualidade.

\section{ABSTRACT \\ PHYSICOCHEMICAL AND SENSORY EVALUATION OF COOKIES PRODUCED USING MORINGA LEAF}

This work aimed at the production of cookies partially substituting wheat flour by Moringa oleifera leaf powder. Three different formulations of cookies were prepared with partial replacement of wheat flour by Moringa oleifera leaf powder in 3.64, 7.27 and 9.09\% corresponding to F1, F2 and F3 respectively. In the sensory evaluation was not observed any difference in acceptance (statistical level of significance of $5 \%$ ) and based on this result it was decided to use the formulation F3 to be compared to standard formulation (SF) in physicochemical analysis. Analysis of ash, moisture, water activity, $\mathrm{pH}$ and titratable acidity of SF and F3 formulations were performed, and similar values were obtained for both formulations. Estimated values of carbohydrates, protein, fiber and fat were calculated and F3 presented higher amounts of fiber and protein in comparison to SF. The levels of fats remained similar and in relation to carbohydrates higher amount was found in the SF formulation in comparison to F3. However, although Moringa leaf has important nutrients for balanced diet, physicochemical analyses are still required to validate the enrichment of foods prepared with this leaf.

KEY-WORDS: Moringa oleifera, COOKIE, SENSORY ANALYSIS.

\section{REFERÊNCIAS}

1 ALVES, M. da C. S.; BEZERRA, A. M. E.; MEDEIROS FILHO, S.; OLIVEIRA, V. C. Germinação de sementes e desenvolvimento de plântulas de Moringa oleifera L. em diferentes locais de germinação e submetidas à pré-embebição. Revista Ciência e Agrotecnologia, Lavras, v. 29, n. 5, p. 1083-1087, set./out. 2005.

2 BARRETO, M. B.; BEZERRA, A. M. E.; FREITAS, J. V. B.; GRAMOSA, M. V.; NUNES, E. P.; SILVEIRA, E. R. Constituintes químicos voláteis e não-voláteis de Moringa oleifera Lam., Moringaceae. Revista Brasileira de Farmacognosia, João Pessoa, v. 19, n. 4, p. 893-897, out/dez., 2009.

3 BRASIL. Agência Nacional de Vigilância Sanitária. Resolução CNNPA n. 12 de 1978. Aprova o regulamento técnico para biscoitos e bolachas. Diário Oficial [da] República Federativa do Brasil. Disponível em: <http://www.anvisa.gov.br/legis/resol/12 78.pdf>. Acesso em: 20 mar. 2010.

4 BRITO, T. M. L. P.; TEIXEIRA, E. M. B. Aceitabilidade do pão francês enriquecido com pó da folha da Moringa oleifera Lam. In: ENCONTRO NACIONAL DE MORINGA, 2009, Aracaju - Sergipe. Disponível em: <www.posgrap.ufs.br/down/Livro_Resumos_17EIC_3EPG.pdf - Similares>. Acesso em 14 abr. 2010.

5 COSTA, Muriene Turcato. Desenvolvimento de cookies com gotas de chocolates - "Cookyttos". In: MOSTRA ACADÊMICA, 6., UNIMEP, 2008, Piracicaba. Disponível em:<www.unimep.br/phpg/ mostraacademica/anais/6mostra/4/391.pdf>. Acesso em 18 mar. 2010.

6 FUGLIE, Lowell. Folhas de moringa secas. Senegal, 2005. Disponível em: <http://tilz.tearfund.org/ Portugues/Passo+a+Passo+41-50/Passo+a+Passo+46/Folhas+de+moringa+secas.htm>. Acesso em: 22 fev. 2010.

7 FUGLIE, Lowell (ed). The miracle tree: Moringa oleifera: natural nutrition for the tropics. Training Manual. Church World Service, Dakar, Senegal. Disponível em: <www.moringatrees.org/moringa/ miracletree.html>. Acesso em: 16 mar. 2002. 
8 FUNDAÇÃO DEUS MAR QUEIRÓS. Moringa a semente da vida. Disponível em:<http://www.moringa. org/ site/index.php?view=article\&catid=36\%3Amoringa-oleifera\&id=47\%3Aa-moringa-oleifera \&option=com_ content\&Itemid=54>. Acesso em: 16 mar. 2010.

9 GOPALAN, C.; SASTRI, R. B.V.; BALASUBRAMANIAN, S. C. Nutritive value of Indian foods. Hyderabad, India: National Institute of Nutrition, 1989. Disponível em: < http://www.ninindia.org/popular.htm>. Acesso em: 20 mar. 2010.

10 INSTITUTO ADOLFO LUTZ. Normas analíticas do Instituto Adolfo Lutz: métodos físico-químicos para análise de alimentos. 4. ed. Brasília, 2005. p. 98 - 105.

11 KERR, W.E.; SILVA, F.R.; RESENDE, A.; GODOI, H.T.; KERR, L.S. Moringa oleifera: distribuição de sementes dessa hortaliça arbórea. Horticultura Brasileira, Brasília, v.16, n.1, p. 159-172, 1998.

12 MACIEL, Leda Maria Braga; PONTES, Dorasílvia Ferreira; RODRIGUES, Maria do Carmo Passos. Efeito da adição de farinha de linhaça no processamento de biscoito tipo cracker. Revista Alimentos e Nutrição, Araraquara, v. 19,n. 4, p. 385-392, out./dez, 2008.

13 MADRONA, G. S. Estudo da extração/purificação do composto ativo da semente da Moringa Oleifera Lam. e sua utilização no tratamento de água de abastecimento. 2009. 197 p. Dissertação (Doutorado em Engenharia Química), Universidade Estadual de Maringá, Maringá, 2009.

14 MAKKAR, H. P. S.; BECKER, K. Nutrients and antiquality factors in different morphological parts of the Moringa oleifera tree. Journal of Agricultural Science, Cambridge, v. 128, n. 3, p. 311-322, May 1997.

15 MATHUR, Balbir S. Um potencial salvador de vidas. Organization Tress For Life, 2005. Disponível em: <http://www.treesforlife.org/our-work/our-initiatives/moringa/moringa-book>. Acesso em: 20 fev. 2010.

16 MONTEIRO, A. R. G. Introdução à análise sensorial de alimentos. Maringá: Eduem, 2005. p. 24-36.

17 MOURA, A. S.; SOUZA, A. L. G.; OLIVEIRA JUNIOR, A. M.; LIRA, M. L.; SILVA, G. L. Caracterização físico-química da folha, flor e vagem da moringa (Moringa oleifera Lamarck). In: ENCONTRO NACIONAL DE MORINGA, 2009, Aracaju - Sergipe. Disponível em: <linux.alfamaweb.com.br/encontromoringa.com. br/.../04-04-ENAM2009.pdf>. Acesso em: 22 jun. 2010.

18 NOVASINA: the art of precision measurement. AW Sprint TH500. 2004. [online] Disponívem em:< www. novasina.com>. Accesso em: 10 maio 2010.

19 NEPA. Núcleo de Estudos e Pesquisas em Alimentação. Tabela brasileira de composição de alimentos (TACO). Versão II. 2. ed. Campinas, 2006. p. 22.

20 OLIVEIRA, I. C.; TEIXEIRA, E. M. B.; PEREIRA, L. A. Aceitabilidade de sorvetes elaborados com leite de soja e enriquecidos com pó de Moringa Oleifera Lam. de diferentes sabores. In: ENCONTRO NACIONAL DE MORINGA, 2009, Aracaju - Sergipe. Disponível em: <linux.alfamaweb.com.br/encontromoringa.com. br/.../04-02-ENAM2009.pdf>. Acesso em: 14 abr. 2010.

21 PINTO, Nayara de Oliveira; HERMES, Luiz Carlos. Sistema simplificado para melhoria da qualidade da água consumida nas comunidades rurais do semi-árido do Brasil. Jaguariuna: EMBRAPA, 2006. Disponível em: <www.cnpma.embrapa.br/public/conta.php3?flag=89>. Acesso em: 10 mar. 2010.

22 ROCHA, I. F; PEREIRA, V. J. Influência do período de armazenamento no desempenho de mudas de moringa (Moringa oleifera LAM.) sob condições de ambiente controlado. In: ENCONTRO NACIONAL DE MORINGA, 2009, Aracaju - Sergipe. Disponível em: <http://linux.alfamaweb.com.br/enam2009.com.br/site/ trabalhos/01-02-ENAM2009.pdf>. Acesso em: 16 mar. 2010.

23 SILVA, A.R.; KERR, W.E. Moringa: uma nova hortaliça para o Brasil. Uberlândia: UFU/DIRIU, 1999. $95 \mathrm{p}$.

24 SILVA, José Monteiro; VIANA, Neuza Ribeiro. Projeto Moringa oleífera: plantio de árvores da saúde. Belo Horizonte: Associação Internacional de Lions Clubes, 2009. Disponível em: <http://www.lionslc4.org. br/PROJETO\%20MORINGA\%20DISTRITO\%20LC4.pdf>. Acesso em: 17 mar. 2010. 
25 UFRJ. Universidade Estadual do Rio de Janeiro. Redução da atividade de água - conservação de alimentos. 2010. Disponível em: <http://acd.ufrj.br/consumo/disciplinas/tt reducaoaw.htm>. Acesso em: 15 jun. 2010. 